\title{
Leadership in improving schools: a qualitative perspective
}

\author{
Clare Penlington, Alison Kington and Christopher Day
}

\section{I ntroduction}

This paper presents findings from the first year of school-based case studies investigating the 'Impact of School Leadership on Pupil Outcomes'. The case study component of this study involved twenty schools (ten primary and ten secondary), all of which were selected on the basis of their sustained improvement (over at least three consecutive years) in terms of pupil outcomes. Interviews were conducted with 20 headteachers, 70 key staff $^{1}$ and 40 colleagues $^{2}$ during each of three terms between autumn 2006 and summer $2007^{3}$. Analysis of the interview data was carried out on each data source and across common themes that were identified through the coding process. In this paper, data are presented which focus on perceptions of the leadership factors that directly and indirectly affect pupil outcomes in these improving schools, and early findings suggest patterns with regard to the leadership practices across the twenty case study schools.

The paper begins by addressing the key themes evident across all of the case study schools: the pivotal role played by the headteacher in setting and communicating a strategic vision for the school within a strong values framework; models of widening participation and distributing leadership to other staff; and, building leadership and teaching capacity within the school so as to build a collective commitment, responsibility and accountability for the improvement of pupil outcomes. The following section focuses specifically on the impact of school context (as measured by pupils' free school meal $\mathrm{FSM}^{4}$ eligibility) on school leadership. The paper then goes on to discuss variations between the schools that contribute to similarities and differences in leadership. In the final section of this paper, we discuss the findings in light of current research.

\footnotetext{
${ }^{1}$ Key staff include deputy headteachers, assistant headteachers, heads of department and key stage coordinators.

${ }^{2}$ Colleagues include teaching and non-teaching staff.

${ }^{3}$ A total of 390 interviews were conducted during the first year of school-based visits. However, the majority of data drawn upon in this paper come from the interviews carried out in the autumn term 2006 and spring term 2007.

${ }^{4}$ Schools were divided into four FSM categories for the purposes of selection and analysis as follows: 0-8\% (FSM1), 9-20\% (FSM2), 21-35\% (FSM 3), and over 36\% (FSM 4).
} 


\section{Mediating improvement in schools: Key themes of successful leadership}

We present four key themes that have emerged from the preliminary case study results, in relation to the effect of school leadership upon pupil outcomes. These are, the pivotal role played by headteacher in leading school success, the complex relationship between leadership distribution and school effectiveness with regard to improved pupil outcomes, the strategies used by leaders to develop capacities within the school, and the effect of school context (measured by FSM) upon leadership approaches. Although each of these themes is presented separately, there are connections between them. The nature of these connections is explored in the concluding sections of this article.

\section{The pivotal role of the headteacher}

Although headteachers certainly did not act alone in leading the case study schools, it is important to note that early results from case studies show that the role of the headteacher is pivotal in ensuring schools' success (a result that contradicts recent research reported by Tymms (O'Shaughnessy, 2007). As previous studies have shown, headteachers play an important role in establishing a school culture which centres around a strong vision for future success (see, for example, Hallinger, 2003; Silins and Mulford, 2002; Waters, Marzano and McNulty, 2005). The early case study data provide us with more specific insights into what it is that headteachers do to establish such a success culture. Key amongst these strategies is establishing and communicating a clear strategic vision for the school, and setting an ethos or culture wherein change and innovation are accepted by staff as necessary to ensure the continued improvement of student outcomes in the school.

\section{Setting a strategic vision}

In outlining reasons for the schools' success in raising student outcomes, $78 \%$ of the participants across all 20 of the case study schools commented on the importance of the headteacher's strategic vision for the school. The success of the headteacher's vision, in terms of how it acted as a positive catalyst for change, seemed to be related to two dimensions. The first of these was the clarity of communication of the vision to staff, students and parents and second was the relevance of the vision to the school context. Put otherwise, key staff commented 
that the success of the headteacher's vision was not simply to do with the strength and clarity of its communication, but also the way that the headteacher's vision was responsive, both to what was happening internally within the school, and in the external environment-including the local community and the broader policy context.

The headteachers' vision, however, was not one of simply responding to what was happening in this external and internals contexts. Rather, the headteachers of the case study schools seemed to have the ability to look to the future so that their vision for change was one that amply prepared the school to respond to future challenges or opportunities. In effect, they (re)positioned the school. For example, a business manager at a Hilltop High School ${ }^{5}$ noted that a crucial aspect of their success could be attributed to the way the headteacher's strategic vision ensured that the school either kept pace, or pre-empted external policy changes in education:

I think one of the biggest strengths she has is that she is prepared, she is very forward thinking and a lot of the things that we have done here have often been, we have been the first people to do it. I mean cover supervisors here are exemplars in the county because we went with it first. So she is quite proactive.

Case study results also show that because headteacher's strategic vision was both clearly communicated and responsive to the many different dimensions of school context (past, present and future, as well as internal and external), staff were more likely to put trust in the headteacher and participate positively in the direction of school change. Thus, although the headteacher's strategic vision was the main driving force behind change within the case study schools, staff did not feel that this was imposed upon them, but that it was a vision that included them and that took the school in a positive direction which result in a collective sense of success. As key staff members in two different schools commented:

He remains very committed, he has a very clear vision that he dedicated to the school, and his leadership style is, in some ways, this is where we're going, and you're all coming with me. (Assistant headteacher at Fairview College)

\footnotetext{
${ }^{5}$ All names of schools are pseudonyms.
} 
[name of headteacher] is an incredible leader, as you obviously have gathered, and I don't know what her secret is except that she's got good interpersonal skills, she's got good organisational skills, she's forward thinking, she has a way of, I don't know, encouraging self-belief in staff. I don't know what she has for breakfast but it works. (Key stage 2 coordinator at Pinehaven Primary)

The headteachers' clear communication of a responsive vision for the school was also important in fostering a culture wherein staff felt empowered as change agents.

\section{Establishing a culture of change}

Forty-nine participants across 18 of the 20 case study schools commented that building a school culture which embraced change and innovation was essential to their school's success in fostering improved student achievement. The role of the headteacher was crucial in fostering this culture of change, in that she or he 'set the tone' for how staff in the school responded to constant changes in external policy and the community environment. In particular, it seems that the ways the headteachers in the case study schools responded constructively to local or national policy initiatives helped to foster a climate where staff viewed participation in change more positively. The proactive way the headteacher at Greenpark Primary evaluated and implemented external policy typifies the stance adopted by headteachers in the case study schools:

I look at it and if I think it has any relevance to something that we're doing they will take it on board. I can give you an example the Social and Emotional Aspects of Learning (SEAL) material. They arrived 18 months ago and I looked at them and thought 'no we don't need' that so I set them aside. Then, later on we were having some discussions and having some difficulties with some children and I thought 'well maybe we should look at those resources, maybe they can support us'.(Headteacher at Greenpark Primary)

She [the headteacher] is constantly embracing what is available, without losing sight of, if you have heard of the expression throwing the baby out with the bathwater. We aren't constantly 
reinventing the school and the wheel, we are trying to keep what we value and what works well, and then extending it.(Deputy Headteacher at Greenpark Primary)

As these comments show, the headteacher at Greenpark primary considered policy changes, not as impositions upon the school, but as opportunities for the school to examine and improve its current practices. In this way, new policies might be implemented, in part or as a whole, in a way that was in keeping in what the school was already doing. They were 'layered' into the life of the school.

The way headteachers in the case study schools encouraged a climate in which change was viewed as a necessary and positive dimension of school culture was commented upon by 41 participants across 16 of the case study schools. These comments show that there were two key strategies used by headteachers in fostering this culture of change: encouraging and supporting staff to introduce innovations in the school, and giving staff a voice in how change might be best implemented:

It's a culture whereby people are free to make suggestions, people are encouraged to think of ways to take the school forward and, from my point of view, I can't think of experiences where staff are actually turned down for anything. So, in terms of trying to boost staff confidence, the culture is one of... it's an open culture. (Key stage 1 coordinator at Roundabout Primary)

Leaders and staff in the case study schools commented that encouraging staff to innovate, and giving them a voice in how change was going to be implemented was important because change and innovation ought not to come from the headteacher alone; instead it should also emerge from within the different layers of leadership in the school. Encouraging staff to play an active role in fostering innovation was considered to be essential by headteachers, key staff and colleagues, because this strategy was a primary means of empowering staff to view themselves as change agents. The following comments represent the main themes in participants' comments about the importance of a wide spectrum of staff participating in change initiatives within the case study schools: 
I've got a teacher in her second year who's been doing some work on... She's a humanities teacher, doing work on developing children's political understanding, getting them involved in citizenship activities and that sort of thing, and she has gone off and done all sorts of things which we're just allowing her to do, because she wants to do them, because she sees them as important. (Headteacher at Sweetwater College)

One teacher has taken up an initiative called, 'Computer clubs for girls'. And she has run with it and they have won an amazing award. And that was someone who has only been teaching for a year. And she felt powerful enough to do that. (Assistant headteacher at Manor High School)

In sum, the headteacher's role of communicating a clear strategic vision that was responsive to the internal and external school context and involved wide participation by a range of staff was critical to the school's success. It was crucial because this strategic vision and planning led to the feeling amongst key staff that the school was at the 'cutting edge', constantly moving forward and improving - a feeling that was a foundation for the development of a school culture where change and innovation were welcomed.

\section{Models of distributed leadership}

For many years researchers have been discussing the concept of distributed leadership (e.g. Copeland, 2003; Smylie \& Denny, 1990; Heller \& Firestone, 1995). Spillane (2001) described this approach to leadership as "practice distributed over leaders, followers in their situation and incorporates the activities of multiple groups of individuals" (p. 20). More recently, in a review of literature relating to successful school leadership, distributed leadership was described as "being a web of leadership activities and interactions stretched across people and situations" (Leithwood et al., 2006, p. 46). Over the last 10 years, literature has supported the notion that distributed, shared (Pearce \& Conger, 2003) collaborative (Wallace, 2002) and participative (Vroom \& Yaho, 1998) leadership are all overlapping concepts (Leithwood et al., 2006). 
Data collected in all case study schools indicated that both headteachers and key staff felt that leadership in their school was distributed amongst staff in some way. It was also reported that distribution, or devolvement, was important to the success of the school in terms of sustaining improved student outcomes. This strategy was important because of it worked to cultivate the ownership and agency of staff, and in so doing, developing the shared vision within the staff team:

Everybody is a leader of something. If you give people the ownership then they will do a good job. If I had to, I would say that my role is monitoring and evaluating what is going on in whatever way it is done, and if something isn't working then that would be the time to find out why that it wasn't. (Headteacher at Valley Primary)

Key staff also provided a definition or rationale for distribution of leadership. However, for them the strategy was most often linked to delegation and, to a slightly lesser degree, used as a means of creating shared ownership of change, decision-making and of developing leadership potential in other staff. These results suggest that heads of department and key stage coordinators prioritised the distribution of leadership as a means of sharing tasks, over developing leadership and ownership of change amongst others:

While I now have a second department who was in charge of Key stage three. So there is a process of delegation there. As regards other people in the department, I tend to feel that if people say "well we are not getting paid in the increments" then I can't really force them. (Head of English at Manor High School)

I delegate as much as I possibly can. It depends on what comes through as to whether I think I have to deal with that or I can give it to somebody else to deal with. (Deputy headteacher at Cranfield Primary)

Nevertheless, systems of distributed leadership worked in different ways across, and had a different impact within, the case study schools. Some headteachers distributed leadership so that others leaders were responsible, or at least had a significant voice in decisions about what happened within the school. Other 
headteachers retained a much closer hold upon decision-making, with the effect that responsibility and authority was not as widely distributed within the school. These two forms of distributed leadership have been referred to as decisional distribution' and 'consultative distribution' (Day et al., 2007, p. 14-15).

An example of 'decisional distribution' is seen at Roundabout Primary School. Roundabout is a community primary school with 388 pupils on roll. Most of the pupils come from local families, some of whom are living in challenging social and economic circumstances, and between $9 \%$ and $20 \%$ are eligible for free school meals (FSM2). The majority of pupils come from white British backgrounds and very few speak English as an additional language. A fifth of the pupils have learning difficulties, which is above the national average. There are a small number of 'looked after' children and children from asylum-seeking families. The attainment of children when they start school is below the national average. One of the main disadvantages the school faces, according to OfSTED and the headteacher, is that the school is based in three buildings which are separated by a main road, the nursery and infant school being based on one side and the junior part of the school on the other. The head, therefore, attempts to ameliorate the situation by emphasing a strong team ethos through a series of regular cross-site meetings.

The headteacher has been in the profession for 40 years and a headteacher for 28 of those. He moved to this school 10 years ago, during which time he has established a good working relationship with colleagues:

Some will see me as being an honest broker, some will probably tell you that I am a two-faced bugger, but when push comes to shove I would hope that they would say that I stand beside them. (Headteacher at Roundabout Primary)

Within the school, there is a well established system of distributed leadership and management that enables staff to contribute effectively in setting priorities and targets, and checking that they are met.

My job is to look at the big picture. To look at what I have got in terms of staff abilities. Unless you sit down and talk to staff, they won't tell you what skills they have got. Once you get the big 
picture of where you want to go, then you start putting in your jigsaw pieces. (Headteacher of Roundabout Primary)

The fact that members of staff are valued is shared with the pupils and results in a desire to do well. The school has experienced improvement between the inspection in 2003 and the most recent inspection in 2007. All leaders, including the governors, are committed to 'raising the bar' to ensure that pupils' achievement is maximised. Development and succession planning is thorough and based on the careful and realistic evaluation of school performance by the headteacher, other members of the Senior Leadership Team, as well as all teaching and non-teaching staff.

Two heads of department, however, commented that this form of distribution meant that they, and their students, had little contact with the headteacher, as illustrated by the following quotation:

I think is that he gives the day-to-day running over to the deputies because I can say hand on heart that I could count on one hand how many interactions I have had with them over the last year... $\mathrm{He}$ is out of school a lot (Head of Maths at Worthington College)

Leaders in the case study schools where this approach to distributed leadership was being adopted noted that a key benefit to distributing leadership in this way was that a wider number of people could take on leadership roles, and so develop their understanding and responsibility for whole-school issues, as opposed to classroom or departmental issues. In total, 31 participants, across 14 schools (9 primary and 5 secondary) commented on the positive relationship between taking on leadership roles and the development of a breadth of vision and responsibility within teachers:

I'll say that one of the differences between teachers and leaders is that you have to have a wider view of what is going on in the school and not just what is going on in your room when you shut the door really. (Assistant headteacher at Cranfield Primary)

Now that I'm not Head of Department any more, and I don't have direct responsibility for any individual, but more responsibility for the way the school's run, you do see the bigger picture, and you do 
realise that, perhaps before, you were tunnel-visioned. (Assistant headteacher at Fairview College)

One of the main issues concerned the extent to which members of staff were clear about their roles and responsibilities. Twenty-one participants (across 11 schools) commented that the effectiveness of the distribution of leadership in their school was linked to the clarity of roles and responsibilities. Clarity of roles and responsibilities was considered to be important to the effectiveness of distributed leadership in that, when lines of communication were clear, leaders knew what their responsibilities were, and staff members knew who to approach for support and guidance:

Obviously we have a good leadership structure, we have got the head, in the deputies in all the different roles. We know what everybody's role is. (Head of English at Worthington College)

As Deputy head I am responsible for everyone, but we have broken down into smaller groups and each person knows to whom they can go to raise issues or concerns or talk about a child. (Deputy headteacher at Greenpark Primary)

In contrast, some headteachers wanted to retain far more control over decisionmaking in the school and adopted a different approach to leadership and distribution of responsibilities within the school ('consultative distribution'). Sweetwater College is a community comprehensive school with approximately 950 11-16 year old students on roll. It is a popular school with low proportions of pupils (0-8\% - FSM1) who qualify for free school meals or who have learning difficulties and disabilities. Few pupils are from minority ethnic groups and almost all speak English as their first language. In recognition of its continuing success, the school achieved 'Leading Edge' status in 2004, receiving extra funding to allow it to work with and support other schools. In September 2005 it was designated a 'Specialist Science' school.

The headteacher is in his fifth year in his first headship, and has taken a dynamic lead in ensuring that the school makes continued improvements. 
I did a survey the very first day I arrived, with staff. 'Write down one thing you feel this school needs to be better at and write down five things you feel the school is really good at'. (Headteacher at Sweetwater College)

He has set a clear direction, and made the school more outward-looking through its involvement in 'Leading Edge' activities and its designation as a 'Specialist Science' school. Senior and middle managers have established strong systems to make sure that all staff do their jobs as well as possible and are involved in the decision-making processes within the school, although the final decision is always left to the headteacher.

The one thing I wouldn't say I am is democratic, because I don't think that is what I am being paid for. In fact, I said to the staff early on, "I do believe very much in listening to people, but please do not think this is a democracy. We are not going to hold a vote every time we want to do anything. It is actually my job to set direction, to be strategic, and to pull everything together and say where we are going. (Headteacher at Sweetwater College)

Through self-evaluation and internal reviews that include the views of pupils, individual subject departments are accountable for the standards they achieve and given targets for improvement. Parents' views are regularly sought and they receive information weekly through the school 'Gazette'. A particular achievement in the school has been the creation of an unusually strong culture of improvement among the teachers. This has largely been achieved through the introduction of research and development activities which have raised expectations, improved teaching and benefited learners.

On a Monday all of our middle leaders are involved in research and development. They have themes that are based against the school development plan and they spend time researching those themes and developing new ideas for teaching and learning. (Headteacher at Sweetwater College)

In summary, early findings from the case study component of this study suggest that, to better understand effective distribution of leadership, it is necessary to examine not only the history of the school and its present structures and 
systems, but also how these are calibrated with the other factors. These include the stage of development of the school, the stage of development of the headteacher's leadership, the length of time headteacher has been in role and the social context of school.

\section{Building capacities}

Based upon a comprehensive review of literature, Leithwood et al. (2006) argue that one probable way in which leadership impacts upon student achievement is that it acts as a "catalyst for unleashing the potential capacities that already exist in the organization" (p. 15). Past research shows that building capacities (knowledge and skills) of staff within school is an important means of achieving school improvement (e.g. Fullan, 2001; Sergiovanni, 2001).

In support of this hypothesis, the early case study results clearly show that headteachers and other leaders place particular emphasis upon building both the teaching and leadership capacities of the staff team, to ensure the continued effectiveness of the school in raising pupil outcomes. Headteachers in all 20 case study schools viewed the development of leadership capacities within their staff team as a central part of their role in at least two respects: to be effective in sustained improvement of student outcomes and; to help individual staff members to develop their leadership skills, careers and sense of efficacy and commitment.

\section{Succession planning}

Participants' comments show that succession planning for emerging school leaders took two main forms. The most important of these were succession strategies that occurred within the school (51 comments: 25 headteacher and 47 key staff, across all 20 schools). There were two main forms. The first of these was the privileging of internal promotion for staff who showed leadership promise. For example, the headteacher at Fairview College had recently made the decision to promote the head of the English department to the role of assistant headteacher, responsible for developing the leadership skills of other heads of department:

He [the head of English] has been a very successful curriculum leader. English has been one of the successful subjects in the school and he's run that successfully for 13 years now, and it's 
right for him to use his expertise on the senior team. What I want him to do is to work with other curriculum leaders to bring them up to the same standard as English and to share ideas, and what I envisage him doing next year as part of his role is having a timetabled meeting once a fortnight with groups of curriculum leaders and for them to share issues and ideas, with him chairing it and chipping in with ideas. That's one of the things that I want him to do, using his experience of leading a department and getting groups of staff to come together and share ideas (Headteacher at Fairview College)

The second form of succession planning was to change staff responsibilities within the school. Case study results indicate that this form of 'horizontal' succession planning was used more by primary headteachers than secondary headteachers (it was specifically mentioned by headteachers in 4 primary schools), which may be a reflection of the limited number of leadership posts within primary schools:

I give them additional responsibilities, and as time goes on change those responsibilities. One of the things that I'm keen to do every year is to reflect on everybody's responsibility and change them so no one will have the same responsibility for ever. Because I think that is deskilling, it means that you haven't tested your management skills in a different area. (Headteacher at Greenpark primary)

Provision of support and guidance for leaders within the school was another important strategy in developing leadership capacity within the case study schools. Foremost amongst these support strategies was that of offering developing leaders forms of support, guidance and nurturing that would assist them to accomplish new responsibilities successfully (mentioned by 27 participants, including 9 headteachers). Four headteachers also made specific mention that it was very important not to blame or criticise staff when they made a mistake in a new leadership role. These headteachers recognised that the development of leadership skills involved a learning curve, and that it was more important for developing leaders to learn from mistakes, than to view them as failures of achievement. As the headteacher at Hilltop High school put it, when outlining her approach to fostering leadership potential of staff: 
You've got to have a go. If you get it wrong, let's not worry about it. I rarely, if ever, take somebody off at the knees. I am quite forgiving because I make a lot of mistakes myself. Usually it's just, 'Have a go, if you get stuck come and see me'. (Headteacher at Hilltop High School)

Another strategy for succession planning (commented on by 27 participants across 14 case study schools) was that of sending staff to leadership courses run by external agencies such as the NSCL, local authorities and the Specialist School's Trust.

\section{Developing teaching capacities}

Developing the pedagogical capacities within the school was a key priority. Comments by 67 participants, across all 20 of the case study schools, showed that it was through developing this pedagogical capacity that schools expected to be able to meet both challenges such as low achievement in particular curriculum areas, or low achievement of a specific group of students (e.g. special education needs students, gifted and talented students, boys' underachievement).

Comments by headteachers and key staff across 17 of the case study schools ( 7 primary and 10 secondary) show that building the teaching capacity of staff was achieved through adopting an increasingly strategic approach to professional development. Broadly speaking, this meant that professional learning programmes were aligned with specific school-wide priorities for developing teaching and learning within the school. Leaders in the case-study schools talked about moving away from a professional development model which relied on sending individual staff to external courses, towards a greater reliance upon inhouse models of professional development. For example, at Sweetwater College the focus of the continuing professional development programme was very clearly purposefully directed towards developing teaching capacities across the staff team, rather than those of individual teachers. The delivery of training programmes for developing teaching capacities at Sweetwater College was achieved in-house, through routines and structures established by the headteacher and led by different staff members:

Thursday evenings is the only meeting the staff have to attend, which is either all together for training, subject teams for training, or in tutor teams for training, and it's all training-focused. It's not 
admin, it's not pushing pieces of paper around, it's trainingfocused. We have a training conference, a teaching and learning conference every year. (Headteacher at Sweetwater College)

Strategic professional development also involved using student achievement data to identify areas of weakness within teaching and learning in the school, and aligning professional development of staff to address these weaknesses. In this way professional development within the case study schools was much more closely linked to the school development plan and pupil assessment data. Furthermore, efforts were made by senior leaders to establish the effectiveness of different professional development strategies, mainly through performance management:

I think we've got quite a tight package of staff development... a lot of in-service has been on curricular targets. So that's why I was giving a lesson demonstration on it to make sure some new members of staff were clear about what we were talking about. And when we do our observations, I will look to see whether particular targets are being used. (Deputy headteacher at Pinehaven Primary)

In summary, development of the capacities (knowledge, responsibilities and skills) of the staff within the case study schools was seen as key to improving the overall performance of the staff team in raising pupil outcomes. This focus on developing capacities was three-pronged: on the one hand working to develop the leadership capacities of staff, on the other building and sustaining commitment and self confidence, and on the other, focusing upon improving the teaching capacity of the staff team (and in particular, of classroom teachers).

\section{Differences in leadership: the effect of school context}

Leaders in the FSM 3-4 case study schools (there are 13 such schools in the case study sample) spoke of facing special challenges in leading within the often troubled communities in which their school was situated. Central amongst these challenges were a lack of parental engagement in their child's education and the recruitment of high quality teaching staff-results that accord with past research on leading schools in challenging communities (see, for example, Muijis, Harris, Chapman, Stoll \& Russ, 2004;Gray 2000). Leaders in the FSM 3-4 case study 
schools, however, commented that they considered these challenges as conditions they had to overcome in order to sustain improved pupil outcomes, rather than as a justification for failure. In other words, leaders in the FSM 3-4 schools took the stance that the school had to compensate for social deprivation, rather than using it as an excuse for the low achievement of students. The following comment by a head of English at Worthington College, (a school in the FSM 4 band) illustrates this leadership stance:

If I wanted to claim on my tombstone the effect I had it would be to get everyone's support, get everyone committed to really trying to teach the kids despite whatever barriers and obstacles there have been. And the locus for them is outside the school, but that doesn't matter, because we still have to try and get on with it.

\section{Parental engagement}

The challenge of parental engagement was clearly greater in FSM 3-4 schools compared to FSM 1-2 schools, in the case studies. In order to meet this challenge, leaders in the more challenging schools talked about having to intensify their efforts to make connections with students' parents, even in the face of continued disengagement from some parents. In short, this intensification involved leaders 'leaving no stone unturned' in their quest to find strategies that would garner increased parental engagement in their child's education. The following comments are typical of this stance by leaders in these challenging schools:

When we have the (parental) interviews we now give them an appointment, we have a whole day now. We get about $88 \%$ attendance. And if they don't attend they get followed up, as to why they didn't attend. So there is no escape! (Headteacher at Mosaic Primary: an FSM 4 school)

I have been keeping a record of who doesn't come to parents evening and we have introduced something called, 'Carers Call', which is an automated telephone call that's sent out to all parents reminding them of the parents' evenings. We send out letters with reply slips so that we try and make sure that parents receive the 
letters. We do try and inform them in plenty of time about them and we do have parents' questionnaires and surveys and things like that - in fact there is one being done at the moment to try and get their views on things. (Assistant headteacher at Broadlane Secondary: an FSM 4 school)

\section{Recruiting high quality staff}

Leaders in the FSM 3 and 4 schools were also aware that recruiting high quality staff, who were committed to working with students with a wide range of needs, was of fundamental importance to the school's success in fostering improved student outcomes. In order to meet the challenge of recruiting high quality staff, leaders in these schools drew upon two strategies. The first of these was to become involved in teacher training, so that leaders could appoint new teachers who had proven their effectiveness within the school (mentioned by leaders in 6 schools):

So as a training school what we try and do is use the links that we've got with [name of university], to try and weed out potential people that we wish to employ in the future. (Assistant headteacher at Shoreway Secondary school)

In many ways, the school grows on its own through our own student teachers. (Deputy headteacher at Handon College)

If I have any strength at all I would say it is in choosing the right people for this place. So I have one [teacher] who was going through college this year and I have a number in my diary and if we have a vacancy I will be phoning her up and saying, "Would you like to come in and have a chat about the job here?" A lot of our teachers come here that way, they come and do a practice and they seem to fit. (Headteacher at Mosaic Primary)

The second strategy, outlined in detail by 8 headteachers in FSM 3-4 schools, was that of ensuring that they employed high quality teachers, who would share the vision established by the headteacher. Development of these recruitment strategies included developing a tougher interview process; only filling teaching 
vacancies if the right candidate was found; and employing teachers who had already proved their capabilities within the school (for instance as a supply teacher, student teacher, or through voluntary work). For example, the headteacher at Greenpark Primary (an FSM 3 school) had adapted the recruitment process at the school so that the first stage was inviting a 'long-list' of applicants to the school, then selecting a short list from this larger pool of potential candidates. During this initial visit, long-listed candidates listened to the headteacher give a short talk about her vision for the school and the expectations she had for staff, as well as being observed leading a short impromptu circle-time activity with a group of children:

We did circle time [with candidates] so that we could see the interaction with the children because a key part of a member of staff is how they interact with children. And it was fascinating, because there were some people who on paper were very strong. But the interaction with children was awful. And any appointment I always go and observe them teaching in their school. I have been down to London, I have been to Leicester, I have been all over. Every teacher here has had me observing teaching in their place of work. (Headteacher at Greenpark Primary)(4HT-R3)

In sum, schools in the FSM 3-4 band in the case study sample faced particular challenges to creating the optimum conditions for raising student outcomes, key amongst these being parental disengagement, and the recruitment of high quality staff. Results from the first year of the case studies suggest that leaders of these schools respond to these challenges, not by drawing on significantly different set of strategies, but intensifying their use of strategies to overcome these potential barriers to pupil learning.

\section{Discussion and Conclusions}

Case study results from the first year of this project highlight the primacy of the headteacher in leading the sustained improvement of pupil outcomes. In support of the results of the literature review for this study (Leithwood at al, 2006), the case study results show that headteachers have very powerful indirect effects upon pupil outcomes, through the way that they directly establish positive, success cultures of teaching and learning in the school. 
The case study data show that an important part of establishing a success culture in schools is that the headteacher's vision is clearly communicated, positive and optimistic in tone, and responsive to school and community context. As Bryk and Schneider (2002) found, the clarity of communication of the headteacher's vision is important to school success in raising pupil outcomes, because a clear vision helps to build a culture of mutual trust, in which staff know what they are meant to be doing, and who to go to when they need support. Furthermore, the positive and optimistic tone of the headteacher's vision is important in establishing a success culture where staff feel that they have opportunity to innovate and are part of a team that can achieve the goal of continuing to foster improved student outcomes (see Hopkins, 2001).

All headteachers who participated in this study distributed leadership in some way. As seen from the illustrative examples, the way in which leadership was distributed within a school by the headteacher varied. These variations were related to size of school, school phase, years in headship, and school context, which together, or in part, interacted to shape the pattern of leadership distribution. For example, when securing his role at Roundabout Primary School, the headteacher began by addressing one of the key issues that was preventing the school from improving in terms of pupil outcomes, that of inconsistencies between Key Stage one and Key Stage two provision that had developed due to the split site. By demonstrating how his many years of previous experience of headship in schools of similar size and context would allow him to gain the respect of the staff, he gained the support of the governing body in setting up a new Senior Leadership Team that comprised key members of staff from all sites and Key Stages, working towards common goals for the first time. Likewise, the headteacher at Sweetwater College implemented innovative changes on arrival. He inherited a staff which was frustrated at the lack of opportunity for promotion and professional development, but was aware that the size of the school did not allow for an increase in senior posts. To address this issue, he developed a system of work shadowing, where members of staff at all levels of seniority could request to shadow any other member of staff to gain insights into their role. This successful strategy resulted in numerous teachers shadowing heads of department, and several heads of departments shadowing the assistant headteachers or the headteacher. 
Regardless of the model of leadership distribution adopted, its success relied upon key components being in place for all case study headteachers. The first was a close and collaborative relationship between the headteacher and the senior leadership team (see, for example, Graetz, 2000). As Little (1990) suggests "collegial interaction at least lays the groundwork for developing shared ideas and for generating forms of leadership that promote improvement" (cited in Leithwood et al, 2006, p. 50). The change towards distributed roles and responsibilities was also linked consistently to broadening participation in, and communications about, change (see, Blase \& Blase, 1999; Nias et al, 1989; Rosenholtz, 1989). Finally, the development of student leadership in some schools was considered to be a means of enhancing pupil outcomes. Although this was still at the developmental stage in the case study schools, it was seen as an important step and complementary to the distribution of leadership to staff.

Building staff capacities to learn, to lead and to teach well was considered to be an important leadership strategy within all of the case study schools. Developing the teaching capacities of the team, through strategically focused professional development aligned to teaching and learning goals, was considered to have a more direct effect upon pupil outcomes, because it effected improvement in teaching approaches in classrooms. Developing the skills and knowledge of emerging leaders was also considered to be important because developing this capacity involved more people in making decisions about the direction of the school- a feature of schools that are more effective in raising pupil outcomes (Harris and Chapman, 2002; Moller et al. 2005; Gurr et al, 2005).

Finally, the first year of the case studies suggests that leaders in schools in more challenging circumstances (FSM 3 and 4 schools) do not necessarily draw upon different leadership strategies compared to their counterparts in less challenging circumstances. Rather, leaders in FSM 3 and 4 schools have to and use a greater range of intensively applied strategies in order to overcome particular issues they face, such as parental disengagement (Muijis, Harris et al. 2004) and the recruitment of high quality staff (Gray, 2000). 


\section{References}

Blase, J. R., \& Blase, J. (1999). Implementation of shared governance for instructional improvement: Principals' perspectives. Journal of Educational Administration, 37(5), 476-500.

Bryk, A. S., \& Schneider, B. (2002). Trust in schools: A core resource for improvement. New York: Russell Sage Foundation.

Copland, M. A. (2003). The Bay Area School Reform Collaborative: Building the capacity to lead. In J. Murphy \& A. Datnow (Eds.), Leadership lessons from comprehensive school reforms (pp. 159-183). Thousand Oaks, CA: Sage.

Copland, M. A. (2003). Leadership of inquiry: Building and sustaining capacity for school improvement. Educational Evaluation and Policy Analysis, 24(4), 375-395.

Day, C., Sammons, P., Harris, A., Hopkins, D., Leithwood, K., Gu, Q., Penlington, C., Mehta, P. \& Kington, A. (in press). DCSF Interim Report - Phase 1: The Impact of School Leadership on Pupil Outcomes. DCSF Report due to be published November 2007.

Fullan, M. (2001). Leading in a culture of change. San Francisco, CA: JosseyBass.

Graetz, F. (2000). Strategic change leadership. Management Decisions, 38(8), 550-562.

Gray, J. (2000). Causing concern but improving: A review of schools' experience. London: Department for Education and Skills.

Gurr, D., Drysdale, L \& Mulford, B. (2005). Successful principal leadership: Australian case studies, J ournal of Educational Administration, Vol 43 (6), pp. 539-551.

Hallinger, P. (2003). Leading educational change: Reflections on the practice of instructional and transformational leadership. Cambridge J ournal of Education, 33(3), 329-351.

Hallinger, P. (2003) 'School leadership development', in J.P. Keeves and R. Watanabe (eds.), International Handbook of Educational Research in the AsiaPacific Region. Dordrecht: Kluwer Academic Publishes.

Harris, A., \& Chapman, C. (2002). Effective leadership in schools facing challenging circumstances. Nottingham, UK: National College for School Leadership (NCSL).

Heller, M. F., \& Firestone, W. (1995). Who's in charge here? Sources of leadership for change in eight schools. Elementary School Journal, 96(1), 65-85.

Hopkins, D. (2001). School improvement for real. London: Falmer Press.

Leithwood, K., Day, C., Sammons, P., Harris, A. \& Hopkins, D. (2006).

Successful School Leadership: what it is and how it influences pupil learning. London, DfES Research Report 800. 
Little, J. W. (1990). The persistence of privacy: Autonomy and initiative in teachers' professional relations. Teachers College Record, 91(4), 509-536.

Locke, E. A. (2002). The leaders as integrator: The case of Jack Welch at General Electric. In L. L. Neider \& C. Schriesheim (Eds.), Leadership (pp. 1-22).

Greenwich, CT: Information Age Publishing.

Marzano, R. J., Waters, T., \& McNulty, B. A. (2005). School leadership that works: From research to results. Alexandria, VA: Association for Supervision and Curriculum Development.

Møller, J., Eggen, A., Fuglestad, O. L., Langfeldt, G., Presthus, A., Skrøvset, S., Stjernstrom, E. and Vedoy, G. (2005). Successful school leadership: the Norwegian case. In Jacobson, S. L., C. Day \& K. Leithwood (Eds.), Journal of Educational Administration, The international successful school principalship project (43) 6, $584-594$.

Muijs, D., Harris, A., Chapman, C., Stoll, L., \& Russ, J. (2004). Improving schools in socieconomically disadvantaged areas - A review of research evidence. School Effectiveness and School Improvement, 15(2), 149-175.

Nias, J., Southworth, G. \& Yeomans, R. (1989). Staff relationships in the primary school (London, Cassell).

O'Shaughnessy, James (Ed) (2001). The Leadership effect: Can headteacher make a difference? London: The Policy Exchange.

Pearce, C. J., \& Conger, C. (2003). Shared leadership: Reframing the hows and whys of leadership. Thousand Oaks, CA: Sage.

Rosenholtz, S. J. (1989). Teachers' workplace: The social organization of schools. New York: Longman.

Sergiovanni, T. (2001). Leadership: What's in it for schools? London: Routledge Falmer.

Silins, H., \& Mulford, W. (2002a). Leadership and school results. In K. Leithwood $\&$ P. Hallinger (Eds.), Second international handbook of educational leadership and administration (pp. 561-612). Dordrecht, The Netherlands: Kluwer.

Silins, H., \& Mulford, W. (2002b). Schools as learning organizations: The case for system, teacher and student learning. Journal of Educational Administration, 40, 425-446.

Smylie, M., \& Denny, J. (1990). Teacher leadership: Tensions and ambiguities in organizational perspective. Educational Administration Quarterly, 26(3), 235-259.

Spillane, J. P., Halverson, R., \& Drummond, J. (2001). Investigating school leadership practice: A distributed perspective. Educational Researcher, 30(3), 2328.

Vroom, V., \& Yago, A. (1998). Situation effects and levels of analysis in the study of leadership participation. In F. Dansereau \& F. Yammarino (Eds.), Leadership: the multiple-level approaches (pp. 145-160). Stamford, CT: JAI Press. 
Wallace, M. (2002). Modelling distributed leadership and management effectiveness: Primary school senior management teams in England and Wales. School Effectiveness and School Improvement, 13(2), 163-186.

Waters, T., Marzano, R. J., \& McNulty, B. (2003). Balanced leadership: What 30 years of research tells us about the effect of leadership on pupil achievement. A working paper. Aurora, CO: Mid-continent Research for Education and Learning. 